Santa Clara University

Scholar Commons

Psychology

College of Arts \& Sciences

$10-2015$

\title{
Relationship education and marital satisfaction in newlywed couples: A propensity score analysis.
}

Rebecca J. Cobb

Kieran T. Sullivan

Santa Clara University, ksullivan@scu.edu

Follow this and additional works at: http://scholarcommons.scu.edu/psych

Part of the Clinical Psychology Commons, Counseling Commons, Counseling Psychology Commons, and the Marriage and Family Therapy and Counseling Commons

\section{Recommended Citation}

Cobb, R. \& Sullivan, K.T. (2015). Relationship education and marital satisfaction in newlywed couples: A propensity score analysis. Journal of Family Psychology, 29,667-678.

Copyright $(\odot 2015$ American Psychological Association. Posted with permission. This article may not exactly replicate the final version published in the APA journal. It is not the copy of record. http://dx.doi.org/10.1037/a0039580

This Article is brought to you for free and open access by the College of Arts \& Sciences at Scholar Commons. It has been accepted for inclusion in Psychology by an authorized administrator of Scholar Commons. For more information, please contact rscroggin@scu.edu. 
Relationship Education and Marital Satisfaction in Newlywed Couples:

\author{
A Propensity Score Analysis \\ Rebecca J. Cobb \\ Simon Fraser University \\ Kieran T. Sullivan \\ Santa Clara University
}

In press at Journal of Family Psychology

Early online publication 2016 


\begin{abstract}
The purpose of this study was to investigate whether premarital relationship education and characteristics of relationship education in a community sample of newlywed couples predicted marital trajectories over 27 months. Newlywed couples $(N=191)$ completed measures of marital satisfaction nine times over 27 months, and prior to marriage they provided information about relationship education and demographic, personal, and relationship risk factors for marital distress. Propensity scores (i.e., the probability of receiving relationship education) were estimated using the marital distress risk factors, and used to derive a matched sample of 72 couples who participated in relationship education and 86 couples who did not. Multi-level analyses of the propensity score matched sample $(n=158)$ indicated that wives who participated in relationship education had declines in marital satisfaction while wives who did not receive relationship education maintained satisfaction over time. Furthermore, the more hours of relationship education the couple participated in, the less steeply their marital satisfaction declined. Findings indicate that participation in community based relationship education may not prevent declines in marital satisfaction for newlywed couples. A possible explanation is that the quality of relationship education available to couples is generally poor and could be greatly improved by inclusion of empirically based relationship information and skills training that are known to lead to stronger marriages.
\end{abstract}

Keywords: relationship education; couples; marital satisfaction; marital trajectories 
Relationship Education and Marital Satisfaction in Newlywed Couples:

A Propensity Score Analysis

To address the serious consequences of relationship distress and divorce, government agencies in many countries have substantially increased funding for, and sometimes mandated, premarital and marital education (Imber-Black, 2005). These policies are based, in part, on growing evidence of the effectiveness of intervening with couples prior to the development of relationship problems, especially in the early years of marriage (Stanley, Amato, Johnson, \& Markman, 2006). Through these interventions, couples can build relationships skills (Blanchard, Hawkins, Baldwin, \& Fawcett, 2009) and prevent relationship distress (e.g., Hawkins, Blanchard, Baldwin, \& Fawcett, 2008). This evidence comes primarily from experimental and quasiexperimental research on the efficacy and effectiveness of specific programs (e.g., Preparation and Relationship Enhancement Program [PREP]; Markman, Floyd, Stanley, \& Storaasli, 1988).

Despite the growing collaboration between relationship researchers and government agencies in developing and disseminating research-based programs (e.g., Halford, Markman, \& Stanley, 2008), the vast majority of couples still participate in untested programs delivered by religious organizations and other community groups, typically just before marriage (Stanley et al., 2006). Program length and content varies considerably; programs that focus on information provision such as readings and lectures are based on the rationale that ignorance about important aspects of relationship functioning underlies the development of relationship problems, whereas programs that focus on couple assessment with instruments such as PREPARE (Olson, Fournier, \& Druckman, 1983) and FOCCUS (Markey, Micheletto, \& Jirgal, 1997) are based on the rationale that awareness of the strengths and weaknesses in the particular relationship is needed. Programs that teach couples skills, such as communication and problem-solving (Stanley et al., 
2001) are based on the rationale that addressing skill deficits will help couples to remain satisfied.

The effectiveness of community programs (treatment as usual) has rarely been directly examined (for a review see Carroll \& Doherty, 2003) and the few published studies have serious methodological limitations (e.g., cross-sectional designs and participants who are married individuals rather than couples). Community-based research is comprised primarily of effectiveness studies of empirically validated programs; these studies contribute little to our knowledge of treatment as usual because they typically employ no-treatment or waitlist control groups (Hawkins et al., 2008; see Laurenceau, Stanley, Olmos-Gallo, Baucom, \& Markman,. 2004, Stanley et al., 2001, and Markman, Rhoades, Stanley \& Peterson, 2013 for exceptions). Thus, there is a critical gap in the research on premarital relationship education (RE) that has important practical implications for policy decisions about the allocation of federal and other funds, particularly regarding how much should be spent on helping or motivating couples to access existing community programs versus dissemination of empirically validated programs.

\section{Effectiveness of Treatment as Usual}

Findings from the few effectiveness studies of RE typically provided in the community are contradictory. In a phone survey of thousands of married individuals with a wide range of marital duration, participation in RE and current marital satisfaction were strongly positively associated (Schumm, Resnick, Silliman, \& Bell, 1998). However, in a similar study of married individuals whose average marital duration was about one year, no such association emerged (Schumm, Silliman, \& Bell, 2000). These contradictory findings may be related to the methodological issues inherent in survey research. First, the variability in participants' length of marriage makes it difficult to ascertain whether RE differentially affects couples in various stages of marriage (e.g., newlywed, transition to parenthood, etc.). Second, relationship 
constructs, such as marital satisfaction, are typically measured with few items (sometimes one) rather than longer, validated instruments. Third, and perhaps most importantly, these studies were cross-sectional, comparing retrospective reports of participation with current relationship functioning (as reported by one spouse). Despite statistical efforts to clarify causation, it remains unclear whether any positive relation between participation in RE and relationship satisfaction is because of an effect of participation on future satisfaction, or because happier couples choose to participate at a higher rate than unhappy couples. Research using longitudinal designs is necessary to shed light on causal relations between participation and subsequent satisfaction.

To address these limitations, we assessed 191 newlywed couples' relationship satisfaction every three months for 27 months, beginning three months prior to marriage, a strategy recommended in previous reviews of RE literature (Blanchard et al., 2009 \& Hawkins et al., 2008). This approach allowed us to examine marital trajectories, rather than satisfaction at one random point, and to control for initial satisfaction when examining the relation between participation and satisfaction trajectories. We also assessed marital risk factors to determine whether RE participation was related to marital outcomes independent of such factors; risk factors included lower age, income, education (e.g., Holman, 2001), and religiosity (Mahoney, 2010), cohabitation before marriage (e.g., Jose, O’Leary, \& Moyer, 2010), depression (Whisman, 2001), neuroticism (Malouff, Thorsteinsson, Bhullar, \& Rooke, 2010), parental divorce (Amato \& Booth, 2001), psychological aggression (Lawrence \& Bradbury, 2007), negative social behavior (Johnson, et al., 2005), and low relationship confidence (Whitton, Olmos-Gallo, Stanley, Prado, Kline, \& St. Peters, 2007) .

To control for risk factors and baseline differences in couples who participate in RE versus not, we used a propensity score matching procedure. A propensity score is the probability, 
based on a variety of factors, of receiving treatment (i.e., RE) versus not (Haviland, Nagin, Rosenbaum, \& Tremblay, 2008). The propensity score is used to select a matched group of treated and untreated participants who are balanced on the observed covariates, which in this case were demographic, personal, and relationship risk factors for marital distress. Propensity score matching is especially important when using a quasi-experimental design, as in this study, because self-selection into RE makes it unclear whether any effects are due to RE or to preexisting group differences. By balancing the RE and no RE groups on a large set of known variables that may be related to selection into treatment and to the outcome of interest, greater confidence in estimating causal effects is warranted (e.g., Graham \& Kurlaender, 2011).

The purpose of this study was to evaluate whether couples who participated in community-based RE had different marital trajectories compared to couples who did not participate. The research is exploratory given the dearth of studies and previous contradictory findings. Considerable efficacy research suggests that participation in RE will be associated with better marital outcomes. However, the only laboratory study that followed treatment-as-usual couples $(N=172)$ found no group differences in marital satisfaction or divorce rates at 18 -month follow-up, despite the finding that participating husbands were more satisfied at the time of participation than non-participating husbands (Sullivan \& Bradbury, 1997). In addition, one community-based study of an empirically validated prevention program (PREP) with a treatment-as-usual control group found no differences in marital satisfaction post-intervention (Stanley et al., 2001) or at one-year follow up (Laurenceau, et al., 2004) between PREP couples and couples receiving naturally occurring interventions. We also examined whether characteristics such as program length, cost, and who provided the RE moderated the association between RE and marital outcomes, as suggested in previous studies (Hawkins, Stanley, 
Blanchard, \& Albright, 2012; Schumm et al., 1998; Stanley et al., 2006).

\section{Method}

\section{Participants}

Participants were a subset $(N=191)$ of 198 heterosexual couples from a two-year study on the transition to marriage. Prior to marriage, $73(38.22 \%)$ of the couples participated in RE, $121(63.35 \%)$ of the couples cohabited, and relationships averaged 4.12 years $(S D=2.86)$. Wives averaged $27.43(S D=4.17)$ years of age, and $16.65(S D=2.45)$ years of education, and average annual income ranged from \$20,000-29,000. Husbands averaged $29.40(S D=4.85)$ years of age, and $16.26(S D=3.11)$ years of education, and their average annual income ranged from $\$ 30,000-39,000$. Of the wives, $71.20 \%$ were Caucasian, $18.85 \%$ were Asian, $5.76 \%$ were Indo-Canadian, 1.05\% were First Nations (Aboriginal Peoples), and 3.14\% identified as "other." Of the husbands, $75.92 \%$ were Caucasian, $14.66 \%$ were Asian, 3.14\% were Indo-Canadian, $1.57 \%$ were Middle-Eastern, $0.52 \%$ were First Nations, and 4.19\% identified as "other;" $21.99 \%$ of the couples were in interracial relationships. Almost half $(47.07 \%)$ of the wives were Christian, $38.10 \%$ had no religion, $2.65 \%$ were Sikh, $2.65 \%$ were Buddhist, $1.59 \%$ were Eastern Orthodox, 1.59\% were Islamic, 1.06\% were Jewish, and 3.70\% were “other.” Almost half $(44.50 \%)$ of the husbands were Christian, $48.17 \%$ had no religion, $2.62 \%$ were Sikh, $2.09 \%$ were Jewish, 1.05\% were Islamic, and 1.05\% were "other."

\section{Procedures}

The University Research Ethics board approved all procedures. Couples were recruited through (a) advertisements in newspapers, on wedding-related electronic bulletin boards, community and campus notice boards, and in businesses that provide wedding-related services;

(b) television and print media coverage; (c) announcements mailed to local religious 
organizations; and (d) information booths at local bridal shows. Interested individuals $(N=617)$ contacted the lab and one member of the couple $(n=493)$ completed a 15-minute telephone or email interview to determine eligibility. Eligible spouses were between 18 and 45 years of age, engaged with a wedding date set, planning first marriages, childless, fluent in reading and writing English, and living in the metro area. Of the 237 eligible couples, 227 agreed to participate, 198 completed at least part of the Time 1 (T1) questionnaires, and 191 couples completed sufficient data to be included in these analyses (i.e., husband and wife provided responses to questions about $\mathrm{RE})$.

Included couples $(n=198)$ were not significantly different from excluded couples $(n=$ 39) on ethnicity, age, duration of cohabitation, or marital satisfaction as assessed during the phone screening (Kansas Marital Satisfaction Questionnaire; Schumm, Nichols, Schectman, \& Grinsby, 1983). Couples completed online questionnaires, once shortly before marriage $(M=$ 3.03 months prior to the wedding; $S D=1.08)(\mathrm{T} 1)$ and approximately every three months thereafter (T2 - T9). Husbands and wives completed T9 on average 27 months $\left(M_{\text {husbands }}=27.68\right.$ months, $S D_{\text {husbands }}=2.40 ; M_{\text {wives }}=27.27$ months, $S D_{\text {wives }}=1.92$ ) following T1. For more details about the sample and procedure, see [author citation].

\section{Measures}

Demographic factors. Participants indicated date of birth, years of education completed, annual income, relationship length, cohabitation prior to marriage, and parental divorce.

Relationship education. At T1 and at T2 (three months later), spouses indicated whether they had participated in any RE prior to marriage. If yes, they also indicated who delivered the RE ("religious leader," "mental health professional," "other"), the cost, number of hours of RE, number of other couples who participated in the RE with them, and who initiated 
participation (“church/religious leader," "me," "partner," "both,” or “other”).

Marital satisfaction. The Quality of Marriage Inventory (QMI; Norton, 1983) is a 6item measure of global marital satisfaction. Total scores were derived by summing the items. Coefficient alphas ranged from .94 to .97 (average across nine waves of data $=.94$ ) for husbands and from .90 to .97 (average across nine waves of data $=.94$ ) for wives.

Relationship confidence. Relationship confidence was assessed with a 4-item measure assessing participants' confidence about their ability to maintain their relationship in the long term (Stanley \& Markman, 1992). Items were rated on a 7-point likert scale and averaged to yield a total score. Coefficient alphas were .90 for husbands and .86 for wives.

Psychological aggression. The Revised Conflict Tactics Scale-2 (CTS2; Straus, Hamby, Boney-McCoy, \& Sugarman, 1996) assessed perceptions of partner psychological aggression in the previous six months. Five psychological aggression items were scored dichotomously $(0=$ no aggression, 1 = any aggression) and summed to yield a total partner-psychological aggression score (cf. Moffitt et al., 1997). Coefficient alphas were .49 for husbands' perceived partner aggression and .57 for wives' perceived partner aggression.

Hostile social behavior. The Test of Negative Social Exchange (TENSE; Ruehlman \& Karoly, 1991) consists of 18 items scored on a 5-point scale that are summed to yield a total score reflecting spouses' perceptions of the frequency of their partner's negative social behavior over the past month (e.g., "In the past month, my partner ignored my wishes or needs"). Coefficient alphas were .88 for husbands and .87 for wives.

Neuroticism. The Neuroticism Scale of the Eysenck Personality Questionnaire (EPQN; Eysenck, \& Eysenck, 1975) assesses neuroticism. Participants responded "yes" or "no" (scored 1 or 0 respectively) to 23 items that were summed to yield a total score. Coefficient alphas 
were .86 for husbands and .88 for wives.

Religiosity. Participants rated their religious behavior and self-identification as religious persons on 4-items (two scored on a 9-point scale, one scored on a 6-point scale, and one scored on a 5-point scale) that were summed to yield a total score (Sullivan, 2001). Coefficient alphas were .90 for husbands and .89 for wives.

Depressive symptoms. The Beck Depression Inventory (BDI; Beck, Steer, \& Garbin, 1988) consists of 21 items scored on 0-3 scale that were summed to yield a total score. Coefficient alphas were .82 for husbands and .88 for wives.

Longitudinal attrition and missing data. Of the 191 couples who were included in analyses and considering only QMI responses, 189 husbands and wives completed T2 (189 couples), 184 husbands and 183 wives completed T3 (181 couples), 166 husbands and 169 wives completed T4 (166 couples), 166 husbands and 168 wives completed T5 (162 couples), 145 husbands and 152 wives completed T6 (142 couples), 160 husbands and 168 wives completed T7 (158 couples), 121 husbands and 132 wives completed T8 (118 couples), and 171 husbands and 175 wives completed T9 (167 couples). Of these, $186(97.38 \%)$ husbands and $187(97.90 \%)$ wives provided at least three waves of data ( $n=186$ couples; $97.38 \%$ of couples). Of the 20 husbands and 16 wives who did not provide T9 QMI data, 4 husbands completed part of the T9 questionnaire, 12 husbands and 12 wives dropped out of the study, and four couples (2\%) had separated or divorced, which is comparable to the divorce rate of $1.8 \%$ in Canada following the second anniversary (Statistics Canada, 2004). Husbands who provided T9 QMI data had more years of education $(M=16.50, S D=3.13)$ and higher relationship confidence $(M=6.54, S D=$ $0.61)$ than husbands who did not complete T9 $\left(M_{\text {education }}=14.20, S D_{\text {education }}=1.99, t(189)=-3.20\right.$, $p=.002, d=.88)\left(M_{\text {relationship confidence }}=6.18, S D_{\text {relationship confidence }}=1.07, t(189)=-2.28, p=.024\right.$, 
$d=.41)$. There were no differences for wives.

\section{Results}

\section{Descriptive Analyses}

Means and standard deviations of study variables are in Table 1. Couples were generally satisfied at T1, on average scoring above the QMI cutoff of 30.5 on a 6-45 point scale (Funk \& Rogge, 2007). At T1, husbands and wives who participated in RE were more religious than husbands $(t(189)=-6.19, p<.001, d=.89)$ and wives $(t(189)=-6.84, p<.001, d=1.00)$ who did not participate. Wives who participated in RE reported higher rates of partner hostile social behavior than wives who did not participate $(t(189)=-2.01, p=.046, d=.30)$. No-RE couples were more likely to cohabit $(73.73 \%)$ than RE couples $(46.57 \%)\left(\chi^{2}(1)=14.32, p<.001, d\right.$ $=.57)$. There were no differences on any other demographic variable between couples who did and did not receive RE. Correlations among T1 variables are in Table 2. Relationship satisfaction was positively related to relationship confidence for both spouses and to religiosity for husbands, and negatively related to income, psychological aggression, hostile social behavior, neuroticism, and depression symptoms for both spouses, and negatively to age for husbands.

\section{Propensity Score Matching Procedure}

Though there were few differences among risk factors between participating and nonparticipating couples, we expected that demographic, personal, and relationship factors could play a role in marital satisfaction trajectories. Thus, we included all risk factors for husbands and wives as covariates in the estimation of propensity scores. Propensity scores were estimated using binary logistic regression and matched samples were derived using the propensity score matching dialogue for SPSS developed by Thoemmes (2001) that utilizes MatchIt, Rltoos, and cem (Hansen, 2004; Hansen \& Bowers, 2008; Ho, Imai, King, \& Stuart, 2007 and 2011). Next, 
we derived a matched sample using 1:5 nearest neighbor matching with replacement and imposed a caliper of .25 of the standard deviation of the logit of the propensity score. The distribution of propensity scores before and after matching with a kernel density estimate overlay is displayed in Figure 1. The matching procedure yielded a sample of 72 RE couples and 86 comparison couples (i.e., no RE). Based on the matching algorithm, 79.52\% of 191 couples were correctly categorized by RE group. Figure 2 includes histograms of the standardized differences between the RE and no RE group before and after matching. The balance of covariates was much improved by the matching procedure and there were no absolute standardized differences on any of the study variables larger than $d=.25$.

\section{Predicting Trajectories of Marital Satisfaction from RE}

Analyses were conducted using the Hierarchical Linear Modeling software program (HLM6.08; Raudenbush, Bryk, Cheong, Congdon, 2000). We used a two-level model that included husband and wife (Atkins, 2005), and repeated measures of marital satisfaction were modeled at Level 1. Time was centered at T1 as zero and then years from T1 to each subsequent time point. Continuous Level 2 predictors were grand mean centered and coefficients were modeled as random (Nezlek, 2001).

We first examined whether there was linear change in marital satisfaction over 27 months in the propensity matched sample using the following equation:

$$
Y_{j}=\beta_{01}(\text { Husband })+\beta_{02}(\text { Wife })+\beta_{11}(\text { Husband Time })+\beta_{12}(\text { Wife Time })+r_{i j}[\text { Equation } 1]
$$

where $Y_{i j}$ is marital satisfaction of each spouse $j$ at Time $i$; $\beta_{01}$ and $\beta_{02}$ represent the mean outcome at $\mathrm{T} 1$ for husbands and wives respectively; $\beta_{11}$ and $\beta_{22}$ represent change in marital satisfaction over time; $r_{i j}$ is the deviation of mean-level marital satisfaction at each assessment

for spouse $j$. We estimated a linear model, which previous research suggests captures systematic 
changes in marital satisfaction (e.g., Lavner, Karney, \& Bradbury, 2013) to examine whether participation in RE differentially predicts declines in satisfaction. As expected and shown in the top panel of Table 3, spouses' marital satisfaction declined over two years. Examination of the variance components indicated that there was significant and sufficient variability in husband slope $\left(\right.$ variance component $\left.=2.48, \chi^{2}(156)=359.67, p<.001\right)$ and wife slope $($ variance component $\left.=3.49, \chi^{2}(156)=289.33, p<.001\right)$ to proceed to the next stage of testing whether RE moderated slopes using the following equations:

Level 1: $\quad Y_{i j}=\beta_{01}($ Husband $)+\beta_{02}($ Wife $)+\beta_{11}($ Husband Time $)+\beta_{12}($ Wife Time $)+r_{i j}$

[Equation 2]

$$
\begin{array}{lll}
\text { Level 2: } & \beta_{01}=\gamma_{010}+\gamma_{011}(\mathrm{RE})+\mu_{01 j} & \text { [Equation 3] } \\
& \beta_{02}=\gamma_{020}+\gamma_{021}(\mathrm{RE})+\mu_{02 j} & \text { [Equation 4] } \\
\beta_{11}=\gamma_{110}+\gamma_{111}(\mathrm{RE})+\mu_{11 j} & \text { [Equation 5] } \\
\beta_{12}=\gamma_{120}+\gamma_{121}(\mathrm{RE})+\mu_{12 j} & \text { [Equation 6] }
\end{array}
$$

At Level 2, $\gamma_{010}$ and $\gamma_{020}$ represent the intercept of the outcome for husband and wife respectively for the couples who did not participate in RE, $\gamma_{011}$ and $\gamma_{021}$ represent the difference between the intercept for husbands and wives who did and did not participate in RE, and $\mu_{01 j}$ and $\mu_{2 j}$ represent residual variance across $j$ participants. Coefficients in Equations 5 and 6 may be interpreted the same way; for example, $\gamma_{110}$ represents the slope of marital satisfaction for husbands who did not participate in RE and $\gamma_{111}$ is the difference between the slope of marital satisfaction for husbands who did not participate and the spouses who did participate in RE.

As shown in the bottom panel of Table 3, wives who participated in RE had significantly steeper declines in marital satisfaction than wives who did not participate in RE (the $t$-test represents the significance of the difference between the slopes for spouse who did and did not 
participate in RE). Specifically, non-participating wives had non-significant declines of 0.36 marital satisfaction points per year and participating wives had significant declines of 1.13 points per year. This represents a $0.07 S D$ unit decline over two years for wives who did not receive $\mathrm{RE}$ and a $0.25 S D$ unit decline per year for wives who did receive RE; wives who received RE had more than 3.5 times steeper declines in satisfaction compared to wives who did not receive RE. Post-hoc analyses of simple slopes revealed that wives who did not receive RE had essentially zero slopes $(t(156)=-1.35, p=.178)$ and wives who received RE had declines in satisfaction over time $(t(156)=-4.45, p<.001)$.

Changes in husbands' marital satisfaction were not moderated by participation in RE, and furthermore, comparison of deviance statistics following constraint of the husband and wife coefficients indicated that the effect of RE as a Level 2 moderator was significantly different for husbands and wives $\left(\chi^{2}(1)=5.93, p=.01, d=.40\right)^{1}$. Finally, the final estimation of the variance component for the husbands' slope was now $0.09\left(\chi^{2}(156)=291.56, p<.001\right)$, as compared to 2.48 in the model that did not include RE, and the variance component for the wives' slope was $0.11\left(\chi^{2}(156)=341.02, p<.001\right)$ in comparison to 3.49 for the model that did not include RE. Thus, after considering RE, significant variability in marital trajectories remains to be explained. To further explore the differences in marital satisfaction between wives who did and did not receive RE, we computed point estimates and confidence intervals for the final data point (T9) for each group in the propensity score matched sample: 40.64 90\% CIs [41.61, 39.69] for no-RE wives and $39.01[40.49,37.54)$ for RE wives. The overlap in CIs is about $65 \%$ of the

\footnotetext{
${ }^{1}$ We also conducted a series of multi-level analyses with the full sample of 191 unmatched couples. First, we examined whether RE moderated changes in marital trajectories, second we controlled for propensity scores at Level 2 in the same analysis, and then finally we examined whether demographic, individual, and relationship risk factors (excluding propensity scores) entered as Level 2 moderators of slopes and intercepts changed the results. We obtained an identical pattern of results in all of these analyses with the unmatched sample, and thus only analyses using the propensity scores are presented for simplicity.
} 
average margin of error, reflecting a marginal difference between the means (cf. Cummings \& Finch, 2005), which is comparable to results of $t$-test comparisons of RE wives $(M=38.71, S D=$ 7.18) and no-RE wives at the end of the study $(M=40.79, S D=5.82 ; t(144)=1.93, p=.056, d$ $=.32)$. In the unmatched sample $(N=191)$ point estimates were $40.5190 \%$ CIs $[41.41,39.61]$ for no-RE wives and 39.02 [37.60] for RE wives; $t$-test comparisons indicated that, RE wives ( $M$ $=38.79, S D=7.16$ ) had lower marital satisfaction by the end of the 2-year follow-up compared to the wives who did not receive $\mathrm{RE}(M=40.96, S D=7.16 ; t(173)=2.18, p=.03, d=.33)$.

We next examined whether spouses fell below the cutoff for marital distress in the unmatched sample (i.e., below 30.5 using a 6-45 scale; Funk \& Rogge, 2007). At T1, 5 no-RE and 4 no-RE husbands and 3 no-RE and 2 RE wives were in the distressed range and by T9, 11 of 171 husbands $(6 \% ; 5$ from the RE group) and 14 of 175 wives (8\%; 8 from the RE group) were in the distressed range; the number of distressed spouses in the RE and no-RE groups were equivalent (for husbands $\chi^{2}(1)=0.28, p=.60$; for wives $\left(\chi^{2}(1)=2.29, p=.13\right.$ ). Finally, we calculated a reliable change criterion based on recommendations from Jacobson and Traux (1992); 37 of 144 husbands had reliable declines in satisfaction, 90 had no reliable change, and 14 had reliable increases in marital satisfaction over two years; chi-square analyses indicated no significant differences in proportions between RE and no-RE husbands. Of the wives $(n=146)$, 13 no-RE and $23 \mathrm{RE}$ wives had reliable declines in marital satisfaction, 58 no-RE and $37 \mathrm{RE}$ wives had no reliable change in satisfaction, and 9 no-RE and 6 RE wives had reliable increases in satisfaction. A chi-square test indicated that there were significant differences on the distribution of improved, stable, and declined wives $\left(\chi^{2}(2)=6.74, p=.03\right.$, Cramer's $\left.V=.15\right)$; follow-up tests indicated that the number of improved wives was equivalent, but fewer RE wives were stable and more RE wives declined compared to wives who did not receive RE. 


\section{Predicting Trajectories of Marital Satisfaction from RE Characteristics}

Next, we examined whether RE characteristics (i.e., provider, cost, number of hours, and number of couples) moderated marital satisfaction trajectories in the matched treatment group (n =72). Hypotheses were tested with equations similar to Equations 2 through 6, with hours, number, and cost entered as continuous variables and provider dummy coded with religious provider as the reference group. Of the $72 \mathrm{RE}$ couples, 51 husbands (70.83\%) and 52 wives (71.23\%) received RE from a religious leader or someone associated with a religious organization, 18 husbands $(25.00 \%)$ and 17 wives $(23.61 \%)$ received it from a mental health professional, and 3 couples $(4.16 \%)$ received it from another source. Husbands reported receiving an average of 11.59 hours $(S D=8.30)$, paying an average of $\$ 85.88(S D=\$ 137.31)$, and participating with an average of 2.78 other couples $(S D=2.34)$. Wives reported receiving an average of 11.57 hours $(S D=7.72)$, paying an average of $\$ 93.22(S D=\$ 135.12)$, and participating with an average of 2.89 other couples $(S D=2.31)$.

As shown in Table 4, type of provider (top panel) and number of couples (bottom panel) did not moderate marital satisfaction trajectories. Husbands who reported paying more for their RE had less steep declines in marital satisfaction than husbands who reported paying less (second panel); however, given the number of non-significant findings for RE characteristics we hesitate to interpret this small effect. Finally, the more hours of RE, the less steep the declines in marital satisfaction (third panel). Post-hoc analyses indicated that simple slopes were significant for husbands who received fewer hours (simple slope $=-.99 ; t(70)=-3.69, p<.001$ ) and more hours of RE (simple slope $=-.95 ; t(70)=3.50, p<.001)$. Similarly, simple slopes were significant for wives who received fewer hours ( simple slope $=-1.31 ; t(70)=-4.27, p<.001$ ), and for wives who received more hours of RE ( simple slope $=-1.25 ; t(70)=-4.02, p<.001$ ). 
To further explore duration as a moderator of declines in marital satisfaction, we conducted post-hoc analyses to compare trajectories of three groups of couples: no-RE couples, relatively shorter duration RE couples, and relatively longer duration RE couples. We created a dummy coded variable to compare these three groups using the median (which was also the modal) number of hours of RE to create the two groups, one with RE hours below the median (10 hours or fewer) and one with RE hours above the median (more than 10 hours). The comparison group was couples who received no-RE. Results of multi-level analyses indicated that there were significant declines in marital satisfaction for husbands who did not receive RE $(S D$ unit coefficient $=-.18, t(155)=-4.54, p<.001)$, which was not significantly different from husbands who received shorter $(S D$ unit coefficient $=-.08, t(155)=-1.03, p=.31)$ or longer duration $(S D$ unit coefficient $=.03, t(155)=0.36, p=.72)$ of RE. The null findings may be due to the reduced variability and restricted range of the dummy coded duration variable. Wives who received shorter duration of RE had significantly steeper declines in marital satisfaction ( $S D$ unit coefficient $=-.19, t(155)=-2.34, p=.02)$, and wives who received longer duration of RE had marginally steeper declines in satisfaction $(S D$ unit coefficient $=-.17, t(155)=1.70, p=.09)$ compared to wives who did not receive $\mathrm{RE}(S D$ unit coefficient $=-.07, t(155)=-1.41, p=.16)$.

We also examined whether who initiated participation in RE was related to trajectories of marital satisfaction. Of the 72 RE couples, 29 husbands and 26 wives indicated that both spouses initiated RE, 9 husbands and 21 wives indicated that they had initiated RE, 17 husbands and 3 wives indicated that their partner had initiated RE, 14 husbands and 19 wives indicated that the church required RE, and 3 couples indicated that RE was initiated by some other source (e.g., a family member). For these analyses, couples who indicated that RE was initiated by the church or another source were combined into an "other" initiated group. As shown in Table 5, 
the source of initiation was unrelated to changes in martial satisfaction. However, spouses who reported that their partner had initiated the RE were relatively less satisfied at $\mathrm{T} 1$ than spouses who reported that they and their partner initiated RE.

\section{Discussion}

We investigated how participating in community-based RE and RE characteristics were related to marital trajectories of a propensity score matched sample of 72 couples who participated and 86 couples who did not participate in RE. Multilevel modeling indicated that RE participation was unrelated to changes in marital satisfaction over 27 months for husbands, but was related to steeper declines in marital satisfaction for participating wives versus nonparticipating wives (who experienced no decline in marital satisfaction). Furthermore, although rates of couples in the distressed range by the end of the study were not different, more wives who received RE declined and fewer remained stable compared to wives who did not receive RE. This finding is somewhat consistent with findings from general effectiveness longitudinal research that RE had no effect on satisfaction over time (Laurenceau et al., 2004; Sullivan \& Bradbury, 1997), and calls into question the findings of retrospective general effectiveness studies that show better marital outcomes for couples who participated in RE (Schumm et al., 1998; Stanley et al., 2006). The differential findings for husbands and wives are intriguing. One possible explanation is that the study duration was insufficient to detect effects of RE on husband's satisfaction, which is consistent with the relatively lower variability in husbands' slopes of satisfaction scores over the 27 months assessed. If it is true that RE affects wives but not husbands' satisfaction, we speculate that this may be due to wives' relatively high desire for change in relationships (e.g., increases in intimacy and support; Heyman, Hunt-Martorano, Malik \& Slep, 2009) and consequent disappointment if RE does not result in positive changes. 
The decline in marital satisfaction observed in participating wives is surprising, and suggests that the RE that couples typically receive in the community is unhelpful. Similar results have emerged in two longitudinal efficacy studies, which provide a possible explanation for our findings. In these two studies, women's increased positive communication in response to an RE program predicted long-term distress and depression (Baucom, Hahlweg, Atkins, Engl, \& Thurmaier, 2006; Schilling, Baucom, Burnett, Allen, \& Ragland, 2003). Authors of these studies suggest that the harmful outcomes may be based on wives' misinterpretation of instructions in communication skills training that "if they are extremely positive and never negative, they are being good wives, and things will improve eventually" (Baucom et al., 2006, p. 452; cf. Stanley, Rhoades, Olmos-Gallo, \& Markman, 2007 and Bodenmann, Bradbury, \& Pihet, 2009 who offer contradictory evidence and an alternate explanations for these findings). Another possible explanation for our finding that RE does not prevent declines in wives' satisfaction is that treatment as usual is focused primarily on assessment and feedback. These types of interventions may raise relationship concerns without providing skills to manage them (e.g., Halford et al., 2008).

Indeed, we found that among participating couples, the effect of RE on satisfaction varied based on the duration of RE. Spouses who spent more time in RE had slower declines in satisfaction compared to spouses who spent less time in RE. Of most importance, wives who received longer duration of RE had only marginally different trajectories from wives who received no RE, who maintained satisfaction over time. We speculate that this is due to the intensity of RE (and we note that high quality programs generally are of longer duration), or to cognitive dissonance (e.g., "I invested so much time in this, I'm really going to use it to make my marriage succeed") or both. This finding replicates the Stanley et al. (2006) finding that the 
duration of RE is related to marital satisfaction. We agree with these researchers that "time spent in education is likely a proxy for intensity and comprehensiveness of services [thus] these finding provide some evidence that better quality RE is linked with better outcomes” (p. 124).

Couples who participated in RE in this study compared to those who did not varied only on a few key variables: cohabitation prior to marriage, husband and wife religiosity, and wives' perceptions of partners' negative social behavior. They did not vary on a host of other potential risk factors for divorce and marital distress (i.e., age, relationship length, years of education, income, parental divorce, relationship confidence, neuroticism, depression symptoms, and psychological aggression). These findings are consistent with many recent studies (e.g., Halford et al., 2006), and suggest that high-risk couples are no more likely to participate in RE than lowrisk couples. The significant difference between participating and non-participating couples on cohabitation is also consistent with past research (Halford O'Donnell, Lizzio, \& Wilson, 2006), as is the difference on religiosity, which may be because most RE programs are offered by religious organizations (approximately $71 \%$ in this sample, comparable to $78 \%$ in Stanley et al., 2006). Finally, spouses who report that their partners initiated RE begin their marriages marginally less satisfied compared to couples where both partners initiated RE. This may be indicative of a lack of investment in the relationship in these spouses. However, spouses' marital trajectories were unaffected by who initiated participation.

Evaluating the effectiveness of RE as typically received in the community is an undertaking fraught with serious methodological challenges, and limitations to our study design must be considered. Although we assessed characteristics of RE such as number of couples, cost, provider, and initiator of RE, we did not have direct measures of the type and quality of program (e.g., informational, skills-based, etc.), or the couples' satisfaction with the RE in which they 
participated. Future research assessing couples satisfaction and the type and quality of the program received could clarify why wives who participated in RE experienced declines in satisfaction compared to wives who did not (cf. Hawkins et al., 2012). Other information, such as the training and qualifications of the provider, would also be helpful to begin teasing out the meaning of these findings. Also, recent research suggests that the effects of RE may not be detectable in periods briefer than three or four years, at least for some couples (e.g., low-risk couples; Halford \& Bodenmann, 2013), thus following couples over a longer period of time might reveal additional or stronger effects than those detected in this study.

Finally, we must consider the degree of demographic risk in this sample given that effects of RE may be more apparent in high-risk samples. This sample of newlywed couples cohabited at rates similar to the population (e.g., Reinhold, 2010), husbands had rates of parental divorce similar to national rates, and wives rates of parental divorce were about half (Statistics Canada, 2006a). The sample was somewhat better educated than people of a comparable age in the Metro-Vancouver area at the time of the study (i.e., $50 \%$ of husbands and $60 \%$ of women held university degrees compared to $33 \%$ of men and $40 \%$ of women generally; Statistics Canada, 2006b). However, they had somewhat lower incomes (\$30-39,000 for husbands and \$20-29,000 for wives in this sample compared to an annual average of $\$ 47,000$ for men and $\$ 30,100$ for women in the general population; Statistics Canada, 2010). Thus, the sample seems at least at comparable risk for distress compared to the population.

Strengths of this study include the longitudinal design with nine waves of data collected over 27 months, multi-level analyses, the relatively large sample size, and the inclusion of couples who are at similar stages of relationship development (i.e., newlywed). We also assessed predictors of marital satisfaction to rule out alternate explanations for differences in 
marital trajectories between couples who did and did not participate in RE. This allowed for the use of propensity score matching, equating the participating and non-participating groups on important covariates. Finally, although not representative, our sample was relatively diverse in terms of ethnicity and religious affiliation.

The major implication of these findings is that treatment as usual in the community may not be helpful for couples in terms of preventing deterioration of marital quality over time. These findings underscore the importance of large-scale effectiveness and dissemination studies of empirically validated programs (see Anderson, 2008 for a special section on dissemination).. Initial findings of dissemination studies in multiple countries are promising (e.g., Halford et al., 2008; Turner \& Sanders, 2006) and suggest that clergy and lay leaders can effectively implement empirically-validated programs.

Understanding what motivates couples to participate in RE may also be critical, given findings that high-risk couples are no more likely to participate in RE than low-risk couples (e.g., Sullivan, Pasch, Cornelius, \& Cirigliano, 2004). Developing effective ways to recruit high-risk couples may be especially important for husbands (so they will be more likely to initiate or coinitiate participation) and in locations where RE is not mandatory. Perhaps most importantly, government agencies, religious organizations and providers of RE need to be aware that making available or even mandating RE that is untested or that lacks an empirical basis may ultimately fail to achieve the goal of providing couples with the skills to develop stable and healthy marriages. Thus, we urge organizations to consider empirically validated programs and we emphasize the importance of the work already begun by researchers collaborating with organizations to deliver effective RE. 


\section{References}

Amato, P. R., \& Booth, A. (2001). The legacy of parents' marital discord: Consequences for children's marital quality. Journal of Personality and Social Psychology, 81, 627-638. doi:10.1037/0022-3514.81.4.627

Anderson, D. A. (2008). Special Series: Dissemination. The Behavior Therapist, 31, 10-21.

Atkins, D. C. (2005). Using multilevel models to analyze couple and family treatment data: Basic and advanced issues. Journal of Family Psychology, 19, 98-110. doi:10.1037/0893-3200.19.1.98

Baucom, D. H., Hahlweg, K., Atkins, D. C., Engl, J., \& Thurmaier, F. (2006). Long-term prediction of marital quality following a relationship education program: Being positive in a constructive way. Journal of Family Psychology, 20, 448-455. doi:10.1037/08933200.20.3.448

Beck, A. T., Steer, R. A., \& Garbin, M. G. (1988). Psychometric properties of the Beck Depression Inventory: Twenty-five years of evaluation. Clinical Psychology Review, 8, 77-100. doi:10.1016/0272-7358(88)90050-5

Blanchard, V., Hawkins, A., Baldwin, S., \& Fawcett, E. (2009). Investigating the effects of marriage and relationship education on couples' communication skills: A meta-analytic study. Journal of Family Psychology, 23, 203-214. doi:10.1037/a0015211

Bodenmann, G., Bradbury, T. N., \& Pihet, S. (2009). Relative contributions of treatment-related changes in communication skills and dyadic coping skills to the longitudinal course of marriage in the framework of marital distress prevention. Journal of Divorce and Remarriage, 50, 1-21. doi:10.1080/10502550802365391

Carroll, J., \& Doherty, W. (2003). Evaluating the effectiveness of premarital prevention 
programs: A meta-analytic review of outcome research. Family Relations, 52, 105-118. doi:10.1111/j.1741-3729.2003.00105.x

Cumming, G., \& Finch, S. (2005). Inference by eye: Confidence intervals and how to read pictures of data. American Psychologist, 60, 170-180. doi:10.1037/0003-066X.60.2.170

Eysenck, H. J., \& Eysenck, S. B. G. (1975). Manual of the Eysenck Personality Questionnaire. Sevenoaks, Kent: Hodder and Stoughton.

Funk, J., \& Rogge, R. (2007). Testing the ruler with item response theory: Increasing precision of measurement for relationship satisfaction with the Couples Satisfaction Index. Journal of Family Psychology, 21, 572-583. doi:10.1037/0893-3200.21.4.572.

Graham, S. E., \& Kurlaender, M. (2011). Using propensity scores in education research: General principles and practical applications. The Journal of Educational Research, 104, 340-353. doi:10.1080/0022067.2010.486082

Halford, W., \& Bodenmann, G. (2013). Effects of relationship education on maintenance of couple relationship satisfaction. Clinical Psychology Review, 33, 512-525. doi:10.1016/j.cpr.2013.02.001

Halford, W. K., Markman, H. J., \& Stanley, S. M. (2008). Strengthening couple relationships with education: Social policy and public health perspectives. Journal of Family Psychology, 22, 497-505. doi:10.1037/a0012789

Halford, W. K., O’Donnell, C., Lizzio, A., \& Wilson, K. L. (2006). Do couples at high risk of relationship problems attend premarriage education? Journal of Family Psychology, 20,160-163. doi:10.1037/0893-3200.20.1.160

Hansen, B. B. (2004). Full matching in an observational study of coaching for the SAT. Journal of the American Statistical Association, 99, $609-618$. 
Hansen, B. B., \& Bowers, J. (2008). Covariate balance in simple, stratified and clustered comparative studies. Statistical Science, 2, 219-236.

Haviland, A., Nagin, D. S., Rosenbaum, P. R., \& Tremblay, R. E. (2008). Combining groupbased trajectory modeling and propensity score matching for causal inferences in nonexperimental longitudinal data. Developmental Psychology, 44, 422-436. doi:10.1037/0012-1649.44.2.422

Hawkins, A. J., Blanchard, S. A., Baldwin, S. A., \& Fawcett, E. B. (2008). Does marriage and relationship education work? A meta-analytic study. Journal of Consulting and Clinical Psychology, 76, 723-734. doi:10.1037/a0012584

Hawkins, A. J., Stanley, S. M., Blanchard, V. L., \& Albright, M. (2012). Exploring programmatic moderators of the effectiveness of marriage and relationship education programs: A meta-analytic study. Behavior Therapy, 43, 77-87.

doi:10.1016/j.beth.2010.12.006

Heyman, R. E., Hunt-Martorano, A. N., Malik, J., \& Slep, M. (2009). Desired change in couples: Gender differences and effects on communication. Journal of Family Psychology, 23, 474-484. doi:10.1037/a0015980

Ho, D. E., Imai, K., King, G., \& Stuart, E. A. (2007). Matching as nonparametric preprocessing for reducing model dependence in parametric causal inference. Political Analysis, 15, 199-236.

Ho, D. E., Imai, K., King, G., \& Stuart, E. A. (2011). Matchit: Nonaparmetric preprocessing for parametric causal inference. Journal of Statistical Software, 42, 1-28.

Holman, T. B., (2001). Premarital Prediction of Marital Quality or Breakup: Research, Theory, and Practice. New York: Kluwer Academic/Plenum. 
Imber-Black, E. (Ed). (2005). Couple relationship education in an international context [Special issue]. Family Process, 44, 139-201.

Jacobson, N. S., \& Truax, P. (1992). Clinical significance : A statistical approach to defining meaningful change in psychotherapy research. In A. E. Kazdin (Ed.), Methodological issues and strategies in clinical research (pp. 631-648). Washington, DC, US: American Psychological Association. doi:10.1037/10109-042

Johnson, M. D., Cohan, C. L., Davila, J., Lawrence, E., Rogge, R. D., Karney, B. R., \& ... Bradbury, T. N. (2005). Problem-solving skills and affective expressions as predictors of change in marital satisfaction. Journal of Consulting and Clinical Psychology, 73, 15-27. doi:10.1037/0022-006X.73.1.15

Jose, A., O'Leary, D. K., \& Moyer, A. (2010). Does premarital cohabitation predict subsequent marital stability and marital quality? A meta-analysis. Journal of Marriage and Family, 72, 105-116. doi:10.1111/j.1741-3737.2009.00686.x

Laurenceau, J. P., Stanley, S. M., Olmos-Gallo, A., Baucom, B., \& Markman, H. J. (2004). Community-based prevention of marital dysfunction: Multilevel modeling of a random effectiveness study. Journal of Consulting and Clinical Psychology, 72, 933-943. doi:10.1037/0022-006X.72.6.933

Lavner, J. A., Karney, B. R., \& Bradbury, T. N. (2013). Newlywed's optimistic forecasts of their marriage: For better or for worse? Journal of Family Psychology, 27, 531-54-. doi:10.1037/a0033423

Lawrence, E., \& Bradbury, T. N. (2007). Trajectories of change in physical aggression and marital satisfaction. Journal of Family Psychology, 21, 236-247. doi:10.1037/08933200.21 .2 .236 
Mahoney, A. (2010). Religion in families, 1999-2009: A relational spirituality framework. Journal of Marriage and Family, 72, 805-827. doi:10.1111/j.1741-3737.2010.00732.x

Malouff, J. M., Thorsteinsson, E. B., Schutte, N. S., Bhullar, N., \& Rooke, S. E. (2010). The Five-Factor Model of personality and relationship satisfaction of intimate partners: A meta-analysis. Journal of Research in Personality, 44, 124-127.

doi:10.1016/j.jrp.2009.09.004

Markey, B., Micheletto, M. P., \& Jirgal, S. A. (1997). FOCCUS: Facilitating open couple communication, understanding and study. Omaha, NB: FOCCUS Inc.

Markman, H. J., Floyd, F. J., Stanley, S. M., \& Storaasli, R. D. (1988). Prevention of marital distress: A longitudinal investigation. Journal of Consulting and Clinical Psychology, 56, 210-217. doi:10.1037/0022-006X.56.2.210

Markman, H. J., Rhoades, G. K., Stanley, S. M. \& Peterson, K. M. (2013) A randomized clinical trial of the effectiveness of premarital intervention: Moderators of divorce outcomes. Journal of Family Psychology, 27, 165-172. doi:10.1037/a0031134

Moffitt, T. E., Caspi, A., Krueger, R. F., Magdol, L., Margolin, G., Silva, P. A., ...Sydney, R. (1997). Do partners agree about abuse in their relationship?: A psychometric evaluation of interpartner agreement. Psychological assessment, 9, 47-56. doi:10.1037/10403590.9.1.47

Nezlek, J. (2001). Multilevel random coefficient analyses of event- and interval-contingent data in social and personality psychology research. Personality and Social Psychology Bulletin, 27, 771-785. doi:10.1177/0146167201277001

Norton, R. (1983). Measuring marital quality: A critical look at the dependent variable. Journal of Marriage and the Family, 45, 141-151. doi:10.2307/351302 
Olson, D. H., Fournier, D. G., \& Druckman, J. M. (1983). PREPARE/ENRICH Counselor's Manual. PREPARE/ENRICH, Inc., P.O. Box 190, Minneapolis, MN.

Raudenbush, S. W., Bryk, A. S., Cheong, Y. F., \& Congdon, R. T. (2001). HLM6: Hierarchical linear and nonlinear modeling. Lincolnwood, IL: Scientific Software International, Inc.

Reinhold, S. (2010). Reassessing the link between premarital cohabitation and marital instability. Demography, 47, 719-733.

Ruehlman, L. S., \& Karoly, P. (1991). With a little flak from my friends: Development and preliminary validation of the Test of Negative Social Exchange (TENSE). Psychological Assessment: A Journal of Consulting and Clinical Psychology, 3, 97-104. doi:10.1037/1040-3590.3.1.97

Schilling, E. A., Baucom, D. H., Burnett, C. K., Allen, E. A., \& Ragland, L. (2003). Altering the course of marriage: The effect of PREP communication skills acquisition on couples' risk of becoming maritally distressed. Journal of Family Psychology, 17, 41-53. doi:10.1037/0893-3200.17.1.41

Schumm, W. R., Nichols, C. W., Schectman, K. L., \& Grigsby, C. C. (1983). Characteristics of responses to the Kansas Marital Satisfaction Scale by a sample of 84 married mothers. Psychological Reports, 53, 567-572. doi:10.2466/pr0.1983.53.2.567

Schumm, W., Resnick, G., Silliman, B., \& Bell, D. (1998). Premarital counseling and marital satisfaction among civilian wives of military service members. Journal of Sex and Marital Therapy, 24, 21-28. doi:10.1080/00926239808414665

Schumm, W. R., Silliman, B., \& Bell, B. R. (2000). Perceived premarital counseling outcomes among recently married army personnel. Journal of Sex and Marital Therapy, 26, 177 186. doi:10.1080/009262300278579 
Stanley, S. M., Amato, P., Johnson, C. A., \& Markman, H. J. (2006). Premarital education, marital quality, and marital stability: Findings from a large, random household survey. Journal of Family Psychology, 20, 117-126. doi:10.1037/0893-3200.20.1.117

Stanley, S. M., \& Markman, H. J. (1992). Assessing commitment in personal relationships. Journal of Marriage and the Family, 54, 595-608. doi:10.2307/353245

Stanley, S. M., Markman, H. J., Prado, L. M., Olmos-Gallo, P. A., Tonelli, L., St. Peters, M., . . \& Leber, B. D. (2001). Community-based premarital prevention: Clergy and lay leaders on the front lines. Family Relations, 50, 67-76. doi:10.1111/j.1741-3729.2001.00067.x

Stanley, S. M., Rhoades, G. K., Olmos-Gallo, P. A., \& Markman, H. J. (2007). Mechanisms of change in a cognitive behavioral couples prevention program: Does being naughty or nice matter? Prevention Science, 8, 227-239. doi:10.1007/s11121-007-0071-8

Statistics Canada (2004). Divorces. Retrieved from http://www.statcan.gc.ca/dailyquotidien/040504/dq040504a-eng.htm

Statistics Canada (2006a). 2006 Census: Educational Portrait of Canada. Retrieved from http://www12.statcan.ca/census-recensement/2006/as-sa/97-560/index-eng.cfm

Statistics Canada (2006b). Family Life - Divorce. Retrieved from http://www4.hrsdc.gc.ca/.3ndic.1t.4r@-eng.jsp?iid=76

Statistics Canada (2010). Economic Well-being. Retrieved from http://www.statcan.gc.ca/pub/89-503-x/2010001/article/11388-eng.htm

Straus, M. A., Hamby, S. L., Boney-McCoy, S., \& Sugarman, D. B. (1996). The revised Conflict Tactics Scales (CTS2): Development and preliminary psychometric data. Journal of Family Issues, 17, 283-316. doi:10.1177/019251396017003001

Sullivan, K. T. (2001). Understanding the relationship between religiosity and marriage: An 
investigation of the immediate and longitudinal effects of religiosity on newlywed couples. Journal of Family Psychology, 15, 610-626. doi:10.1037/0893-3200.15.4.610

Sullivan, K. T., \& Bradbury, T. N. (1997). Are premarital prevention programs reaching couples at risk for marital dysfunction? Journal of Consulting and Clinical Psychology, 65, 24-30. doi:10.1037/0022-006X.65.1.24

Sullivan, K. T., Pasch, L. A., Cornelius, T., \& Cirigliano, E. (2004). Predictors of participation in premarital prevention programs: The health belief model and social norms. Family Process, 43, 175-194. doi:10.1111/j.1545-5300.2004.04302004.x

Thoemmes, F. (2011). An SPSS R menu for propensity score matching. Available at arxiv.org.

Turner, K. M. T., \& Sanders, M. R. (2006). Dissemination of evidence-based parenting and family support strategies: Learning from the Triple P--Positive Parenting Program system approach. Aggression and Violent Behavior, 11, 176-193. doi:10.1016/j.avb.2005.07.005

Whisman, M. A. (2001). Marital adjustment and outcome following treatments for depression. Journal of Consulting and Clinical Psychology, 69, 125-129. doi:10.1037/0022006X.69.1.125

Whitton, S. W., Olmos-Gallo, P., Stanley, S. M., Prado, L. M., Kline, G. H., St. Peters, M., \& Markman, H. J. (2007). Depressive symptoms in early marriage: Predictions from relationship confidence and negative marital interaction. Journal of Family Psychology, 21, 297-306. doi:10.1037/0893-3200.21.2.29 
Table 1

Descriptive Statistics for Study Variables

\begin{tabular}{|c|c|c|c|c|c|c|c|c|c|c|}
\hline & \multirow{3}{*}{$\begin{array}{c}\text { \# of } \\
\text { Items }\end{array}$} & \multirow[b]{3}{*}{ Range } & \multicolumn{4}{|c|}{$\underline{\text { No Relationship Education }}^{\mathrm{a}}$} & \multicolumn{4}{|c|}{$\underline{\text { Relationship Education }}^{\text {b }}$} \\
\hline & & & \multicolumn{2}{|c|}{ Husband } & \multicolumn{2}{|c|}{ Wife } & \multicolumn{2}{|c|}{ Husband } & \multicolumn{2}{|c|}{ Wife } \\
\hline & & & $M$ & $S D$ & $M$ & $S D$ & $M$ & $S D$ & $M$ & $S D$ \\
\hline Age & - & - & 29.51 & 4.42 & 27.73 & 3.89 & 28.96 & 5.49 & 26.96 & 4.57 \\
\hline Years of Education & - & - & 16.54 & 3.23 & 16.82 & 2.59 & 15.80 & 2.86 & 16.37 & 2.18 \\
\hline Relationship Length & - & - & 4.13 & 2.54 & 4.13 & 2.54 & 4.10 & 3.35 & 4.10 & 3.35 \\
\hline Relationship Confidence & 4 & $1-7$ & 6.51 & 0.66 & 6.52 & 0.60 & 6.49 & 0.72 & 6.52 & 0.59 \\
\hline Psychological Aggression & 5 & $0-5$ & 1.23 & 1.23 & 1.17 & 1.30 & 1.22 & 1.22 & 1.18 & 1.25 \\
\hline Hostile Social Behavior & 12 & $0-48$ & 14.60 & 9.05 & 11.20 & 8.08 & 15.29 & 9.50 & 13.64 & 8.27 \\
\hline Neuroticism & 23 & $0-23$ & 6.16 & 4.90 & 9.66 & 5.68 & 5.97 & 4.92 & 10.60 & 5.42 \\
\hline Religiosity & 4 & $4-29$ & 10.76 & 7.14 & 9.68 & 6.56 & 18.47 & 8.21 & 16.83 & 8.93 \\
\hline Depression Symptoms & 21 & $0-63$ & 4.93 & 4.48 & 5.52 & 6.03 & 4.00 & 4.93 & 6.18 & 6.61 \\
\hline T1 Relationship Satisfaction & 6 & $6-45$ & 41.33 & 4.68 & 41.79 & 4.07 & 40.79 & 5.67 & 41.56 & 4.27 \\
\hline T2 Relationship Satisfaction & & & 40.83 & 4.92 & 41.79 & 4.69 & 41.56 & 4.03 & 41.78 & 4.75 \\
\hline T3 Relationship Satisfaction & & & 41.63 & 4.36 & 41.62 & 4.71 & 41.64 & 4.51 & 42.12 & 3.90 \\
\hline T4 Relationship Satisfaction & & & 40.85 & 5.22 & 40.97 & 4.97 & 41.59 & 3.80 & 40.77 & 5.36 \\
\hline T5 Relationship Satisfaction & & & 40.87 & 4.74 & 42.22 & 4.05 & 40.98 & 5.31 & 40.46 & 6.22 \\
\hline T6 Relationship Satisfaction & & & 40.26 & 5.81 & 41.40 & 4.43 & 40.90 & 5.13 & 40.75 & 4.80 \\
\hline T7 Relationship Satisfaction & & & 39.50 & 6.68 & 40.54 & 6.61 & 39.93 & 6.50 & 40.68 & 6.30 \\
\hline T8 Relationship Satisfaction & & & 40.47 & 5.00 & 40.27 & 6.98 & 40.55 & 6.04 & 39.86 & 5.28 \\
\hline T9 Relationship Satisfaction & & & 40.12 & 5.70 & 40.95 & 5.87 & 39.09 & 6.34 & 38.79 & 7.16 \\
\hline
\end{tabular}

Note. ${ }^{\mathrm{a}} n=118$ and ${ }^{\mathrm{b}} n=73$ at $\mathrm{T} 1$. 
Table 2

Correlations Among Study Variables for Unmatched Sample

\begin{tabular}{|c|c|c|c|c|c|c|c|c|c|c|c|c|}
\hline & & 1 & 2 & 3 & 4 & 5 & 6 & 7 & 8 & 9 & 10 & 11 \\
\hline 1. & Age & $.73 * *$ & .15 & $.47 * *$ & -.03 & $-.15 *$ & -.10 & -.16 & -.01 & -.02 & -.17 & .02 \\
\hline 2. & Years of Education & $.18^{*}$ & $.30 * *$ & .02 & .10 & -.07 & -.04 & -.01 & .07 & -.04 & .00 & -.08 \\
\hline 3. & Income & $.47 * *$ & $.21 * *$ & $.34 * *$ & .11 & $-.21 * *$ & .00 & $-.15^{*}$ & .01 & -.01 & $-.21 * *$ & -.03 \\
\hline 4. & T1 Relationship Length & .07 & $.20 * *$ & .11 & - & .00 & .12 & -.07 & .06 & .06 & $-.19 * *$ & -.01 \\
\hline 5 . & T1 Relationship & -.11 & -.04 & $-.16^{*}$ & .00 & $.44 * *$ & $-.21 * *$ & $.76 * *$ & $-.45 * *$ & $-.31 * *$ & $.18^{*}$ & $-.32 * *$ \\
\hline 6. & $\begin{array}{l}\text { Satisfaction } \\
\text { Perceptions of } \\
\text { Psychological Aggression }\end{array}$ & .03 & -.04 & .00 & $.16^{*}$ & $-.39 * *$ & $.49 * *$ & $-.18^{*}$ & $.37 * *$ & $.29 * *$ & -.07 & $.15^{*}$ \\
\hline 7. & Relationship Confidence & $-.16^{*}$ & $-.16^{*}$ & $-.15 *$ & .02 & $.65 * *$ & $-.33 * *$ & $.33 * *$ & $-.43 * *$ & $-.27 * *$ & .19 & $-.28 * *$ \\
\hline 8. & Hostile Social Behavior & -.07 & -.11 & .04 & .05 & $-.54 * *$ & $.48 * *$ & $-.28 * *$ & $.35 * *$ & $.33 * *$ & -.08 & $.28^{*}$ \\
\hline 9. & Neuroticism & .03 & .07 & $.12^{+}$ & -.04 & $-.38 * *$ & $.34 * *$ & $-.22 * *$ & $.34 * *$ & $.12^{+}$ & -.04 & $.61 * *$ \\
\hline 10 & Religiosity & -.20 & $-.15^{*}$ & $-.24 * *$ & $-.18 *$ & .08 & $-.13^{+}$ & .05 & .04 & -.01 & $.69 * *$ & -.11 \\
\hline 11. & Depression Symptoms & .14 & -.04 & $.12^{+}$ & -.02 & $-.37 * *$ & $.19 * *$ & $-.19 * *$ & $.28 * *$ & $.54 * *$ & -.10 & $.20 * *$ \\
\hline
\end{tabular}

Note. $\quad N=191$ at T1. Correlations within husbands' data appear above the diagonal, correlations within wives' data appear below the diagonal, and cross-spouse correlations are bold and appear on the diagonal.

${ }^{+} p<.10 ; * p<.05 ; * * p<.01$ 
Table 3

Predicting Trajectories of Relationship Satisfaction Over 27 Months From Relationship Education in Propensity Score Matched Sample

\begin{tabular}{|c|c|c|c|c|c|c|c|c|}
\hline & \multicolumn{4}{|c|}{ Husbands } & \multicolumn{4}{|c|}{ Wives } \\
\hline & $B$ & $S E$ & $t$-test & SD Units & $B$ & $S E$ & $t$-test & SD Units \\
\hline Intercept of Marital Satisfaction $^{a}$ & 41.52 & 0.31 & $132.52 * *$ & 0.17 & 41.70 & 0.32 & $129.64 * *$ & 0.15 \\
\hline Slope of Marital Satisfaction ${ }^{a}$ & -0.94 & 0.18 & $-5.14 * *$ & -0.18 & -0.78 & 0.20 & $-3.93 * *$ & -0.15 \\
\hline \multicolumn{9}{|l|}{ Intercept of Marital Satisfaction $^{b}$} \\
\hline Intercept (No RE) & 41.47 & 0.42 & $99.55 * *$ & 0.16 & 41.47 & 0.44 & $93.82 * *$ & 0.11 \\
\hline RE & 0.10 & 0.63 & 0.16 & 0.02 & 0.52 & 0.64 & 0.81 & 0.10 \\
\hline \multicolumn{9}{|l|}{ Slope of Marital Satisfaction ${ }^{b}$} \\
\hline Intercept (No RE) & -0.89 & 0.26 & $-3.41 * *$ & -0.17 & -0.36 & 0.26 & -1.41 & -0.07 \\
\hline RE & -0.11 & 0.36 & -0.29 & -0.02 & -0.95 & 0.40 & $-2.40 *$ & -0.18 \\
\hline
\end{tabular}

Note. $n=158$ couples at $\mathrm{T} 1,{ }^{\mathrm{a}} d f=157,{ }^{\mathrm{b}} d f=156 . S D$ units were calculated by standardizing the outcome within the Level 1 file (across husbands and wives and across all waves of assessment) and then using the standardized variables in secondary multilevel analyses to put the effects presented into standard deviation units. RE = Relationship Education.

${ }^{+} p<.10 ;{ }^{*} p<.05 ; * * p<.01$ 
Table 4

Predicting Trajectories of Marital Satisfaction From Characteristics of Relationship Education

\begin{tabular}{|c|c|c|c|c|c|c|c|c|}
\hline & \multicolumn{4}{|c|}{ Husbands } & \multicolumn{4}{|c|}{ Wives } \\
\hline Intercept (Religious Provider) & 41.72 & 0.59 & $70.93 * *$ & 0.17 & 42.34 & 0.55 & $76.43 * *$ & 0.29 \\
\hline $\begin{array}{l}\text { Mental Health Professional } \\
\text { Provider }\end{array}$ & -0.64 & 1.13 & -0.57 & -0.12 & -1.65 & 1.10 & -1.50 & -0.30 \\
\hline Other Provider & -0.06 & 2.48 & -0.03 & -0.01 & 0.72 & 2.36 & 0.30 & 0.13 \\
\hline \multicolumn{9}{|l|}{ Slope of Marital Satisfaction ${ }^{a}$} \\
\hline Intercept (Religious Provider) & -0.78 & 0.32 & $-2.43 *$ & -0.14 & -1.28 & 0.37 & $-3.49 * *$ & -0.24 \\
\hline Other Provider & 0.18 & 1.28 & 0.14 & 0.03 & 0.37 & 1.52 & 0.24 & 0.07 \\
\hline \multicolumn{9}{|l|}{ Intercept of Marital Satisfaction ${ }^{b}$} \\
\hline Intercept (Low Cost) & 41.57 & 0.48 & $86.95 * *$ & 0.15 & 41.98 & 0.46 & $91.20 * *$ & 0.22 \\
\hline Higher Cost & 0.00 & 0.00 & 0.17 & 0.00 & 0.00 & 0.00 & -1.62 & -0.00 \\
\hline \multicolumn{9}{|l|}{ Slope of Marital Satisfaction ${ }^{\mathrm{b}}$} \\
\hline Intercept (Low Cost) & -1.01 & 0.25 & $-4.07 * *$ & -0.19 & -1.34 & 0.30 & $-4.48 * *$ & -0.25 \\
\hline \multicolumn{9}{|l|}{ Slope of Marital Satisfaction ${ }^{b}$} \\
\hline Intercept (Low Hours) & -0.99 & 0.24 & $-4.01 * *$ & -0.18 & -1.31 & 0.29 & $-4.48 * *$ & -0.24 \\
\hline High Hours & 0.04 & 0.02 & $2.00^{*}$ & 0.01 & 0.06 & 0.03 & $2.06^{*}$ & 0.01 \\
\hline \multicolumn{9}{|l|}{ Intercept of Marital Satisfaction $^{\mathrm{b}}$} \\
\hline Intercept (Low Number of Couples) & 41.56 & 0.48 & $86.82 * *$ & 0.15 & 41.98 & 0.46 & $90.38 * *$ & 0.22 \\
\hline High Number of Couples & -0.01 & 0.17 & -0.09 & -0.00 & -0.03 & 0.16 & -0.17 & -0.01 \\
\hline \multicolumn{9}{|l|}{ Slope of Marital Satisfaction ${ }^{b}$} \\
\hline Intercept (Low Number of Couples) & -1.00 & 0.25 & $-4.04 * *$ & -0.19 & -1.33 & 0.30 & $-4.48 * *$ & -0.25 \\
\hline High Number of Couples & 0.10 & 0.10 & 0.99 & 0.02 & -0.07 & 0.09 & -0.75 & -0.01 \\
\hline
\end{tabular}

Note. $n=72$ at $\mathrm{T} 1,{ }^{\mathrm{a}} d f=69 ;{ }^{\mathrm{b}} d f=70$. SD units were calculated by standardizing the outcome within the Level 1 file (across husbands and wives and across all waves of assessment) and then using the standardized variables in secondary multilevel analyses to put the effects presented into standard deviation units.

${ }^{+} p<.01 ; * p<.05 ; * * p<.01$ 
Table 5

Predicting Marital Trajectories From Initiation

\begin{tabular}{|c|c|c|c|c|c|c|c|c|}
\hline & \multicolumn{4}{|c|}{ Husbands } & \multicolumn{4}{|c|}{ Wives } \\
\hline & $B$ & $S E$ & $t$-test & SD Units & $B$ & $S E$ & $t$-test & SD Units \\
\hline \multicolumn{9}{|l|}{ Intercept of Marital } \\
\hline \multicolumn{9}{|l|}{ Satisfaction } \\
\hline Intercept (Both Initiated) & 42.73 & 0.64 & $65.87 * *$ & 0.36 & 42.86 & 0.68 & $62.53 * *$ & 0.38 \\
\hline Partner Initiated & -3.27 & 1.03 & $-3.16 * *$ & -0.60 & -4.22 & 2.02 & $-2.09 *$ & -0.78 \\
\hline Self Initiated & -1.93 & 1.33 & -1.45 & -0.36 & -0.97 & 0.98 & -0.99 & -0.18 \\
\hline Other Initiated & -0.76 & 1.01 & -0.76 & -0.14 & -1.46 & 0.97 & -1.49 & -0.27 \\
\hline \multicolumn{9}{|l|}{ Slope of Marital Satisfaction } \\
\hline Intercept (Both Initiated) & -0.78 & 0.38 & $-2.03^{*}$ & -0.14 & -0.84 & 0.48 & $-1.72^{+}$ & -0.15 \\
\hline Partner Initiated & -0.51 & 0.62 & -0.82 & -0.09 & 0.37 & 1.39 & 0.27 & 0.07 \\
\hline Self Initiated & 0.24 & 0.78 & 0.31 & 0.05 & -1.05 & 0.69 & -1.50 & -0.19 \\
\hline Other Initiated & -0.54 & 0.61 & -0.88 & -0.10 & -0.54 & 0.71 & -0.76 & -0.10 \\
\hline
\end{tabular}

Note. $n=72$ at T1, $d f=68$. SD units were calculated by standardizing the outcome within the Level 1 file (across husbands and wives and across all waves of assessment) and then using the standardized variables in secondary multilevel analyses to put the effects presented into standard deviation units.

${ }^{+} p<.10 ; * p<.05 ; * * p<.01$ 
Unmatched Treated

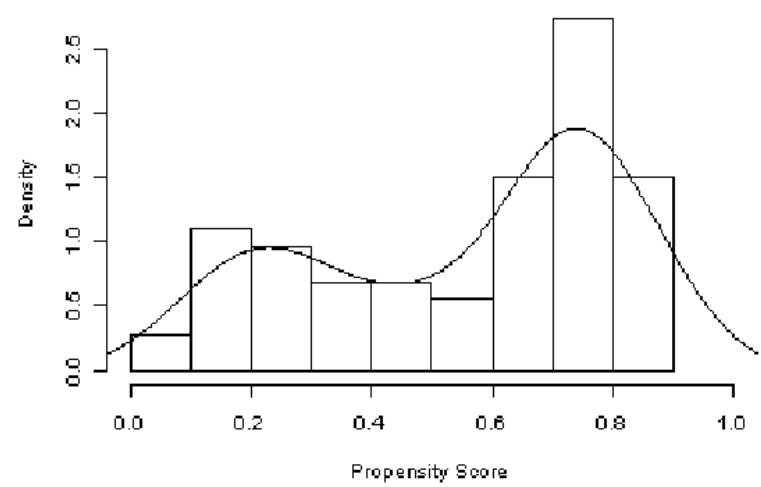

Unmatched Control

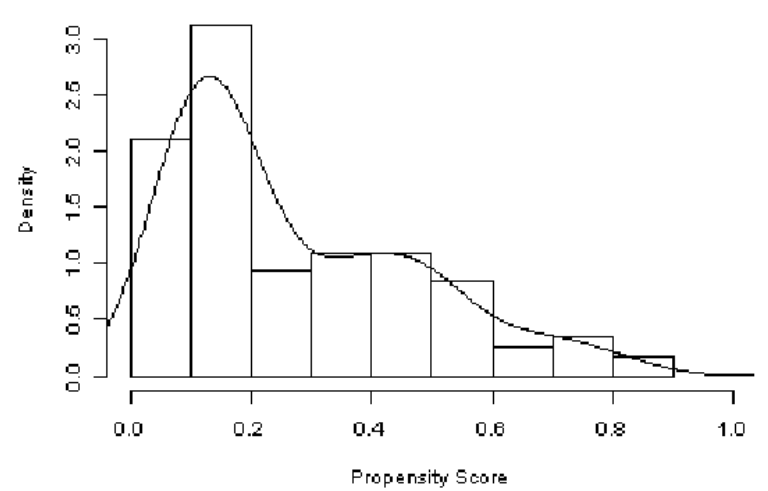

Matched Treated

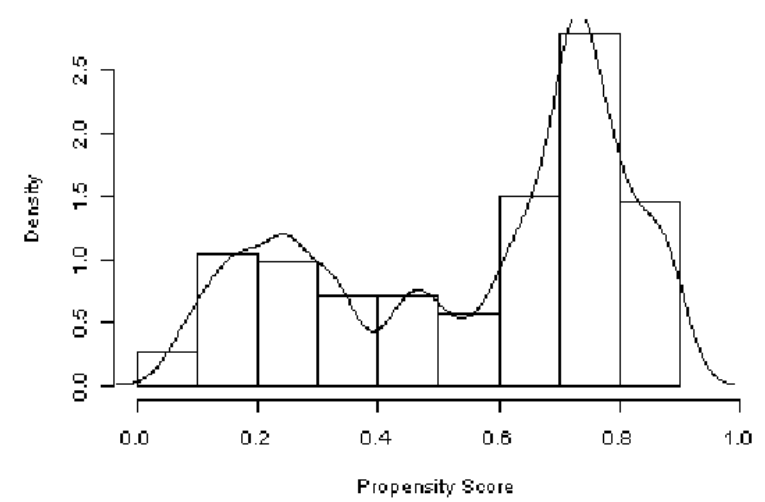

Matched Control

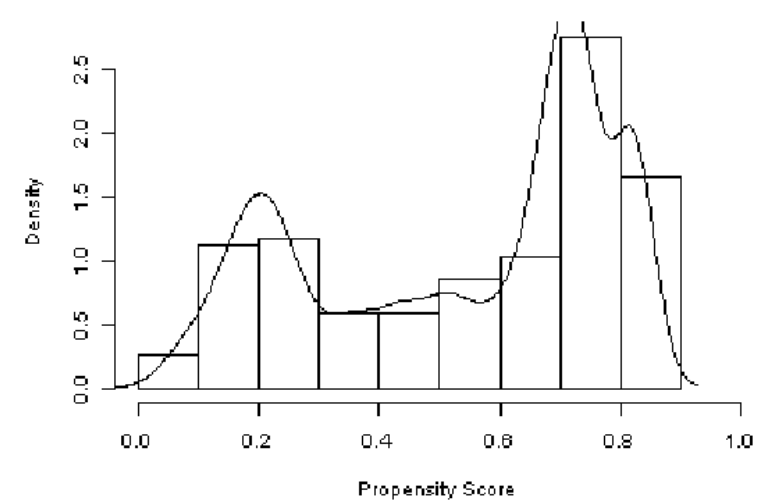

Figure 1. Distribution of propensity scores of couples who participated in relationship education ("treated") and couples who did not ("control") before and after matching with overlaid kernel density estimate. Graph was produced using modified routines of the MatchIt package. 


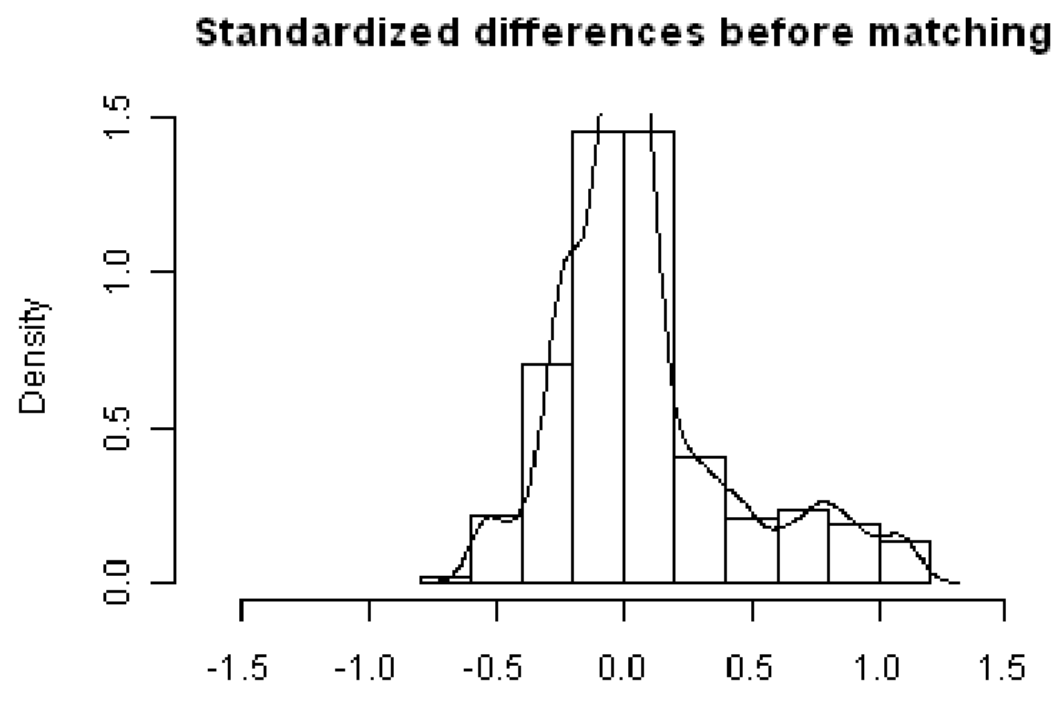

Std. difference

Standardized differences after matching

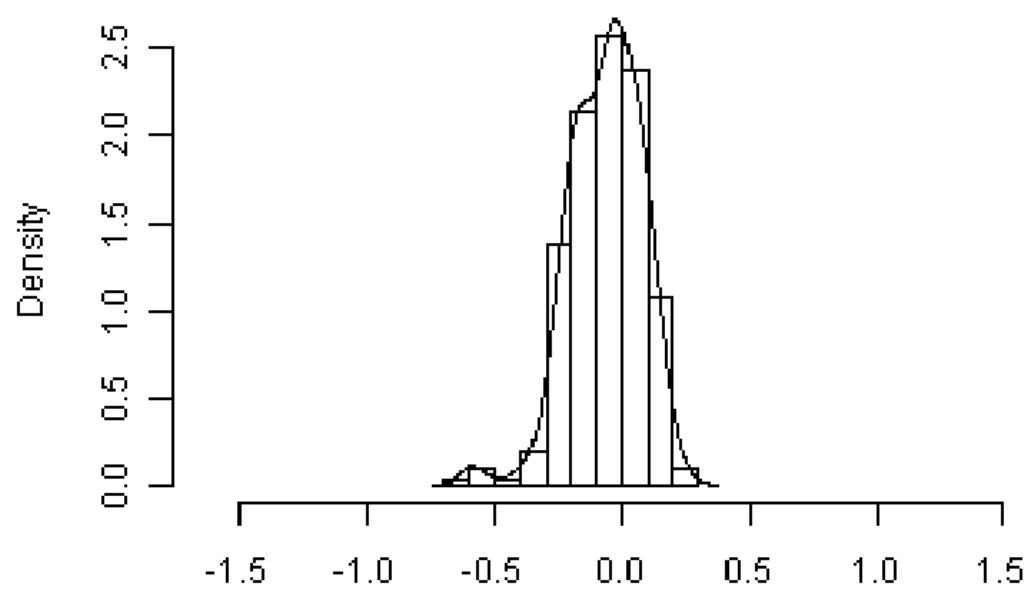

Std. difference

Figure 2. Histograms with overlaid kernel density estimates of standardized differences before and after matching. Graph was produced using modified routines of the MatchIt package. 